\title{
COMPARATIVE STATISTICAL ANALYSIS OF NEUTRAL WIND IN MID-LATITUDE MESOSPHERE / LOWER THERMOSPHERE BASED ON METEOR RADAR AND FABRY-PEROT INTERFEROMETER DATA
}

R.V. Vasilyev

Institute of Solar-Terrestrial Physics SB RAS, Irkutsk, Russia,roman_vasilyev@isz.irk.ru

\section{M.F. Artamonov}

Institute of Solar-Terrestrial Physics SB RAS, Irkutsk, Russia, artamonov.maksim@mail.iszf.irk.ru

\section{E.G. Merzlyakov}

Institute for Experimental Meteorology,

Science and Production Association "Typhoon",

Obninsk,Russia,evgmer@gmail.com

\begin{abstract}
Studies of the upper atmosphere wind are very important both for understanding the mechanism of transformation of exposure energy into heating, movement and chemical activity of the atmosphere, and similar processes of energy transfer from lower to upper atmospheric layers. Instruments and methods for studying the wind velocity and its variations at different height levels usually complement each other in such studies. We perform a comparative analysis of information about the neutral horizontal wind over Eastern Siberia in the winter-spring period obtained by different methods. We observe some features appearing at different heights during geomagnetic storms and sudden stratospheric warming events. We propose a method for comparative statistical analysis of the neutral wind registered at different sites and show its validity. Using this method, we make a quantitative comparison of winds measured over Eastern Siberia in the winter-spring period. The wind measured by the meteor radar and Fabry-
\end{abstract}

Perot interferometer at $90 \mathrm{~km}$ has similar direction and absolute velocity. The wind measured by the FabryPerot interferometer at $100 \mathrm{~km}$ differs from that estimated by the meteor radar only in direction. The wind measured by the Fabry-Perot interferometer at $250 \mathrm{~km}$ has a velocity 2.5 times faster and a direction differing by $30-40^{\circ}$ from the wind obtained by the meteor radar.

Keywords: meteor radar, Fabry-Perot interferometer, horizontal wind, mesosphere, lower thermosphere, geomagnetic storm, sudden stratospheric warming, statistical correlation analysis.

\section{INTRODUCTION}

Simultaneous observations of wind velocity and temperature by optical and radiophysical methods provide useful information on features of aeronomy and circulation of the upper atmosphere. Although the rather widely-spaced ground observing stations cannot give so detailed picture of the global distribution of parameters of the upper atmosphere as satellite systems, they have much higher time resolution. This allows us to observe features of the local behavior of the atmosphere associated with changes caused by seasonal and diurnal variations as well as by sudden stratospheric warming (SSW) events or geomagnetic activity. Moreover, independent detection methods not only confirm the obtained information but also complement each other, thus providing a more complete picture of a phenomenon under study.

Collaborative studies of wind behavior in the upper atmosphere with a Fabry-Perot interferometer and meteor radar have been carried out many times. Studies of this kind, which have shown a significant role of wave processes as a source of errors in determining horizontal wind velocity by a partial reflection technique, were used, say, to verify new observation methods [Hines et al., 1993]. Simultaneous observations of wind using the $843 \mathrm{~nm}$ hydroxyl airglow spectrum and radio echoes from meteor trails [East et al., 1995] have re- vealed that the optical method is valid for further development of the neutral wind model because the wind parameters identified by a radiophysical method are integrated in a wide range of heights $(75-110 \mathrm{~km})$, whereas the hydroxyl airglow layer is quite thin $(6 \mathrm{~km})$. The authors also attributed the differences in observations made using different methods to the rather large distance between observation stations. Plagmann et al. [1998], studying the wind by optical and radiophysical methods, due to a smaller distance between observation points than that in [East et al., 1995] have demonstrated a high degree of correlation between observed wind velocities and have proposed a correlation method for determining the height of hydroxyl airglow. Yu et al. [2017] have applied a similar method for identifying the hydroxyl airglow layer. Fujii et al. [2004] have examined vertical variations in the $557.7 \mathrm{~nm}$ atomic oxygen airglow layer from meteor echo observations by a radiophysical method. Salah et al. [1999] when observing a specific region of the upper atmosphere by optical and radiophysical methods have also shown a high degree of correlation between wind data. The authors attributed the differences in the results to statistical errors, different geometry of scanned areas, and presence of local gradients and small-scale inhomogeneities throughout the observable atmosphere. Similar observations were made both in independent studies [Jiang et al., 2012; Jee 
et al., 2014] and in international observation campaigns [Hu et al., 2014]. Studies of features of the behavior of the upper atmosphere during strong geomagnetic storms based on such observations allow us to estimate the vertical dynamics of air-mass transport. Shiokawa et al. [2003] observed a two hour delay of variations in the mesospheric wind as against the thermospheric one during a large-scale ionospheric disturbance caused by a magnetic storm. Studies of SSW events with a set of optical and radiophysical tools make it possible to verify atmospheric circulation models and determine variations in global parameters of planetary waves in these events [Wu et al., 2016]. In this paper, we describe and comparatively analyze joint Fabry-Perot interferometer and meteor radar observations of wind velocity in the upper atmosphere at middle latitudes, in the time zone $+8 \mathrm{UT}$.

\section{BRIEF DESCRIPTION OF INSTRUMENTS AND METHODS OF OBSERVATION}

Horizontal neutral wind velocities in the mesosphere and lower thermosphere (MLT) were measured with the radar meteor complex MK-31 installed in Angarsk $\left(52.5^{\circ} \mathrm{N}, 103.8^{\circ} \mathrm{E}\right)$ and with the Keo Scientific's Arinae Fabry-Perot Interferometer installed in Tory $\left(51.7^{\circ} \mathrm{N}\right.$, $\left.103.1^{\circ} \mathrm{E}\right)$. Location of these instruments and their fields of view are shown schematically in Figure 1.

The Fabry-Perot Interferometer (FPI) makes regular spectrophotometric observations of 557.7, 630, and $843 \mathrm{~nm}$ nightglow. The precision spectral analysis allows us to monitor the Doppler shift of an individual line, which characterizes the velocity of respective radiating atmospheric component along the line of sight of the instrument. The Doppler shifts obtained in different directions within an interval of stationarity of medium enable us to reconstruct the full vector of horizontal velocity of glowing gas. Vertical stratification of emission lines in the upper atmosphere permits determining the horizontal velocity vector at various heights. FPI with $\sim 0-15$ min time resolution observes 630.0 and $557.7 \mathrm{~nm}$ atomic oxygen airglow lines with characteristic airglow heights of 250 and $100 \mathrm{~km} \mathrm{re}-$ spectively. Since 2018, FPI has also monitored the 843 nm hydroxyl line (a characteristic airglow height is 90 $\mathrm{km})$. The instrument and method of observation are described in more detail in [Vasilyev et al., 2017a, b].

The MK-31 complex includes a VHF radar with an operating frequency of $46.3 \mathrm{MHz}$. When detecting a radio echo from unsaturated ionized meteor trail, MR sounds this MLT region by radio frequency pulses with $400 \mathrm{~Hz}$ repetition rate and $100 \mu$ s duration. The velocity of a neutral atmospheric component is estimated from the velocity of horizontal transfer of a meteor trail. The station is the next generation of radio meteor radars designed by the Scientific-Production Association "Typhoon" and used to study the wind regime of the MLT region since 1964 [D'yachenko et al., 1986]. The measurements are made without determining the height of the trail that scatters a signal from the station.

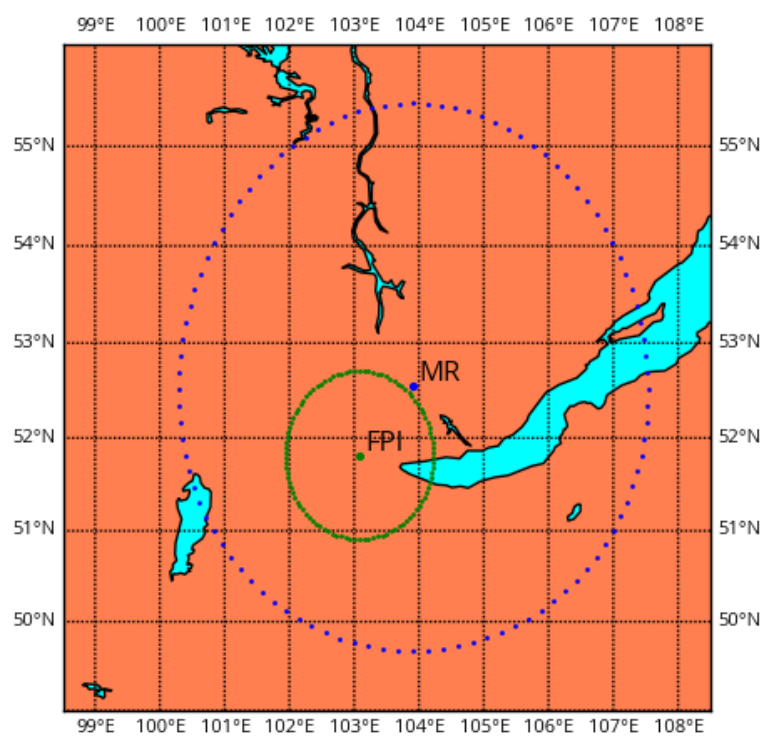

Figure 1. Schematic of the location of the instruments and projection of scanned areas on Earth's surface: FPI is the Fabry-Perot interferometer, MR is the meteor radar

The obtained hourly average wind velocities are therefore attributed to the average height of a maximum number of radio echoes from sporadic meteors. The distribution of radio echoes from sporadic meteors represents a normal distribution with an average of $90 \mathrm{~km}$ and a width of $\sim 14 \mathrm{~km}$ at a half-maximum level [Jacobi, 2014].

\section{DESCRIPTION OF OBTAINED DATASETS}

To compare the wind data obtained with the interferometer and meteor radar, we have selected two time intervals: 01.01.2017-05.31.2017 and 01.01.2018-03.31.2018. Color maps that partially characterize datasets of both the instruments are given in Figures 2, 3. Each map represents the diurnal and seasonal variations in the zonal wind velocity as derived from FPI and MR data under different observing conditions. Zero on the time scale ( $\mathrm{Y}$-axis) on these maps means the local solar midnight; negative values indicate the evening time (before midnight); positive ones, the night and morning time (after midnight). Gaps in the datasets result from temporary stops in observations, caused by equipment malfunctions, as well as from Moon background illumination (empty slops in FPI data). The solid black line shows variations in the $A_{\mathrm{p}}$ index reflecting geomagnetic activity; the dashed black line indicates the moment of development of the sudden stratospheric warming event on January 25, 2017. Notice that until January 16, 2017 the interferometer worked in incorrectly set temperature stabilization mode of etalon, providing data with higher variance. For the beginning of the stratospheric warming event in this paper we take a significant increase in the average zonal temperature at a level of $10 \mathrm{hPa}$, further averaged in the range of 55 to $75^{\circ} \mathrm{N}$. These data are taken from the official website of NASA Atmospheric Chemistry and Dynamics Laboratory 
[https://acd-ext.gsfc.nasa.gov/Data_services/met/ ann data.html].

The maps for 2017 (Figure 2) show that when geomagnetic activity increases, the moment of inversion of the zonal wind at $250 \mathrm{~km}(630 \mathrm{~nm}$ line $)$ shifts to the beginning of the night in almost all the cases. According to FPI observations of the $557.7 \mathrm{~nm}$ line and MR data there are no such well-defined zonal wind variations with geomagnetic activity at $\sim 100 \mathrm{~km}$. Before the SSW event (January 10-25, 2017) at $250 \mathrm{~km}$, no significant changes in the circulation occur. At the same time, as derived from the $557.7 \mathrm{~nm}$ line observations, at $100 \mathrm{~km}$ in the second half of the night there is quite a strong westward wind, which slightly weakens before the SSW event. On the day of the SSW onset there is a total inversion of the zonal wind at $100 \mathrm{~km}$ and a significant decrease in the wind at $250 \mathrm{~km}$; there are no data from a height of $90 \mathrm{~km}$ for this day. Given the short-term character of the change and its coincidence for both spectral lines detected by FPI, we can say that a possible cause of this change can be the poor quality of observations during this day (severe weather conditions). After beginning of the SSW event at $100 \mathrm{~km}$ there is a shortterm (7-10 days) anomaly in the regular diurnal variation of the zonal wind, but there are no pronounced changes in the diurnal variation of the zonal wind at 250 $\mathrm{km}$. There are no such variations at $90 \mathrm{~km}$ on February 1-14, 2017, either. A reason for this may be the difference between heights at which the observations are made or a greater interval of averaging of meteor radar data $(1 \mathrm{~h})$ as compared to that of interferometer data (10 $\mathrm{min})$, as well as a combination of these factors. Not counting the above deviations caused by natural processes, the datasets obtained with MK-31 and FPI, which worked in the $557.7 \mathrm{~nm}$ line, generally have a greater similarity in this time interval.
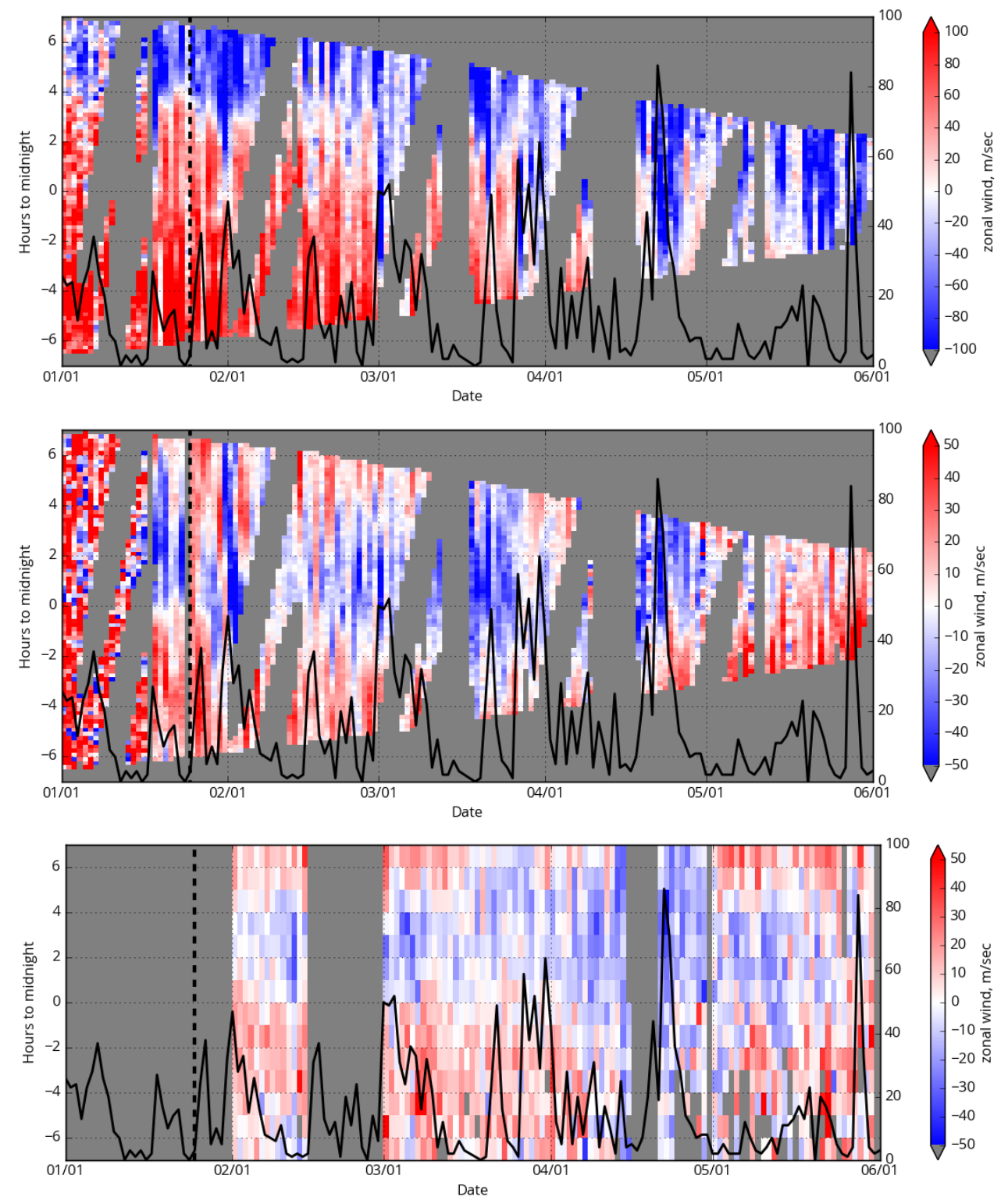

Figure 2. Color maps of seasonal and diurnal zonal wind variations from January to May 2017, obtained with (from top to bottom): FPI in the $630 \mathrm{~nm}$ line $(\sim 250 \mathrm{~km})$; FPI in the $557.7 \mathrm{~nm}$ line $(\sim 100 \mathrm{~km})$; MR $(\sim 90 \mathrm{~km})$; the solid line is the $A_{\mathrm{p}}$ index, the dashed line is the moment of the SSW event onset on January 25, 2017 
The data on the zonal wind for 2018 presented in Figure 3 show a greater similarity of the wind observed by MK-31 with the wind measured by FPI in the $843 \mathrm{~nm}$ hydroxyl airglow, rather than with the wind observed in the 557.7 $\mathrm{nm}$ line. A reason for this is most likely to be the location of the hydroxyl airglow layer, which is closest to the height of the maximum number of detected sporadic meteors - 90 $\mathrm{km}$. In Figure 3, as in Figure 2, the solid line shows geomagnetic activity variations during observations; the dashed line indicates the beginning of the SSW event. There were no significant geomagnetic storms during the period of interest. Before the SSW onset on February 12, 2018 (the date has been selected according to the same criteria as in 2017), there is an increase in the eastward wind; and the day before the date, there can be a wind inversion. The prevailing westerly wind at a height of $90 \mathrm{~km}$ remains unchanged for about 10 days. Then there is a short-term (5-7 days) decrease in the wind, after which the zonal wind has a stable diurnal variation up to the end of March, with the east-to-west inversion in the near-midnight hours. Such wind variation also occurs at $100 \mathrm{~km}$, but a decrease in the wind after the SSW event is less pronounced.

The difference in the wind behavior during different SSW events may be caused by features of the local behavior of the upper atmosphere. Data on the meridional wind in the form of diagrams are not presented, but they are qualitatively similar: meridional wind at $250 \mathrm{~km}$ is stronger and does not vary during SSW events, whereas the wind at $100 \mathrm{~km}$ and below does not vary during geomagnetic disturbances. The behavior of the meridional
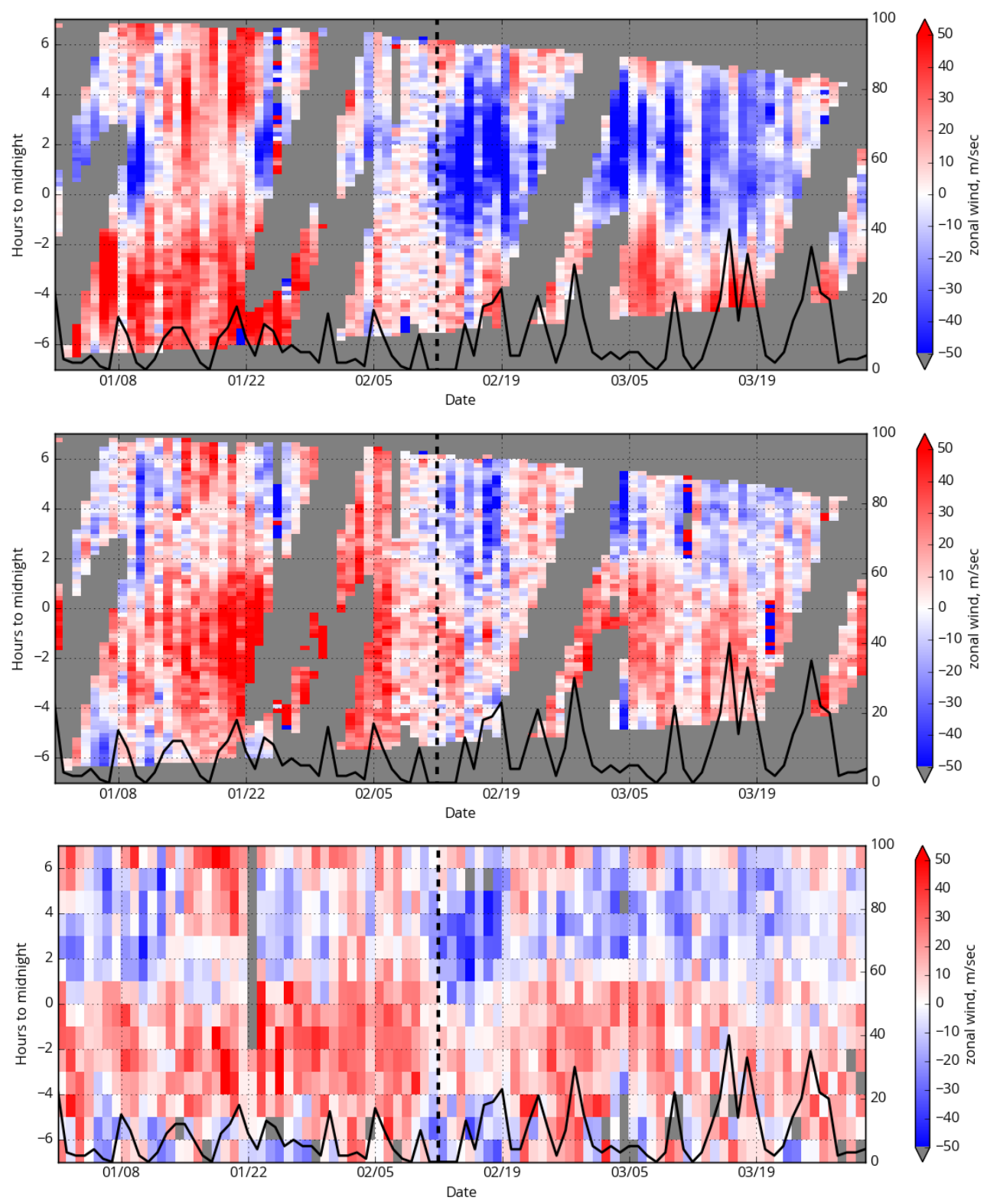

Figure 3. Color maps of seasonal and diurnal variations in the zonal wind from January to March 2018 obtained with (from top to bottom): FPI in the $557.7 \mathrm{~nm}$ line $(\sim 100 \mathrm{~km})$; FPI in the $843 \mathrm{~nm}$ line $(\sim 90 \mathrm{~km})$; MR $(\sim 90 \mathrm{~km})$; the solid line is the $A_{\mathrm{p}}$ index; the dashed line is the beginning of the SSW event on February 12, 2018 
wind differs for the SSW events considered. It should be noted that the horizontal wind variations described above are generally consistent with the average data obtained from 20-year horizontal wind observations in this region [Vergasova, Kazimirovsky, 2010].

\section{COMPARISON OF WIND BEHAVIOR BASED ON DATA FROM DIFFERENT INSTRUMENTS}

Diagrams in Figures 2, 3 quite clearly illustrate the behavior of the horizontal wind, detected with various instruments at different heights. These diagrams can be used for a qualitative comparative analysis of the characteristics. For example, it can be seen that the average wind velocity at $250 \mathrm{~km}$ according to FPI data is higher than that at $90 \mathrm{~km}$ according to MR data. We can also say that the sign of the zonal wind inversion at $250 \mathrm{~km}$ in the spring of 2017 according to FPI data differs from that of the zonal wind inversion at $90-100 \mathrm{~km}$ according to FPI and MR data. It can be noted that the variations in the wind obtained from FPI observations of the 843 nm hydroxyl line are more synchronous with the variations of the wind measured by MR, as compared to the variations of the wind derived from FPI observations in the $557.7 \mathrm{~nm}$ oxygen line. However, such a descriptive comparison as purely qualitative is not always convenient.
To quantitatively compare data from the two instruments, we first used the Pearson and Spearman statistical criteria. We calculated correlation coefficients between the average hourly horizontal neutral wind components obtained with MK-31 and those obtained with FPI for different spectral lines. We also obtained coefficients of linear relationship between horizontal wind components observed with different instruments. Results of these quantitative comparisons are presented in Table. As seen from these values, according to the above criteria the FPI datasets obtained in the $843 \mathrm{~nm}$ line are most similar to the MR datasets, the FPI datasets obtained in the $557.7 \mathrm{~nm}$ line have a lesser degree of similarity, and the FPI datasets acquired in the 630 $\mathrm{nm}$ line are least similar to the MR datasets. This result is logical since the nightglow in the $630 \mathrm{~nm}$ line appears significantly higher than the nightglow in the 843 and $557.7 \mathrm{~nm}$ lines; the latter, in turn, appears near heights of maximum number of recorded sporadic meteors.

To quantify the differences in wind for the heights and methods of interest, two horizontal wind components can be represented as a complex number:

$$
U_{\mathrm{A}, \mathrm{T}}+i V_{\mathrm{A}, \mathrm{T}}=A_{\mathrm{A}, \mathrm{T}} e^{i \theta_{\mathrm{A}, \mathrm{T}}},
$$

Coefficients of correlation between hourly average horizontal neutral wind components obtained with MK-31 and FPI for different spectral lines

\begin{tabular}{|c|c|c|c|c|c|c|}
\hline Data for analysis & $P$ & $\mathrm{p}$-val $(P)$ & $S$ & p-val $(S)$ & $A$ & $B$ \\
\hline $\begin{array}{l}2017 \text { FPI (5577 } \AA) \\
\text { and MR zonal wind }\end{array}$ & 0.217 & $1.3 \cdot 10^{-6}$ & 0.207 & $4.3 \cdot 10^{-6}$ & 0.141 & -0.557 \\
\hline $\begin{array}{l}2017 \text { FPI (5577 } \AA) \\
\text { and MR meridional wind }\end{array}$ & 0.379 & $1.4 \cdot 10^{-20}$ & 0.354 & $5.7 \cdot 10^{-18}$ & 0.266 & -3.285 \\
\hline $\begin{array}{l}2017 \text { FPI ( } 6300 \AA) \\
\text { and MR zonal wind }\end{array}$ & 0.217 & $1.4 \cdot 10^{-6}$ & 0.271 & $1.3 \cdot 10^{-9}$ & 0.055 & 0.272 \\
\hline $\begin{array}{l}2017 \text { FPI }(6300 \AA) \\
\text { and MR meridional wind }\end{array}$ & 0.188 & $7.8 \cdot 10^{-6}$ & 0.230 & $4.1 \cdot 10^{-8}$ & 0.068 & -2.221 \\
\hline $\begin{array}{l}2018 \text { FPI }(5577 \AA) \\
\text { and MR zonal wind }\end{array}$ & 0.424 & $5.5 \cdot 10^{-33}$ & 0.413 & $2.5 \cdot 10^{-31}$ & 0.293 & 3.411 \\
\hline $\begin{array}{l}2018 \text { FPI }(5577 \AA) \\
\text { and MR meridional wind }\end{array}$ & 0.335 & $3.0 \cdot 10^{-22}$ & 0.324 & $7.2 \cdot 10^{-21}$ & 0.221 & -1.248 \\
\hline $\begin{array}{l}2018 \text { FPI ( } 6300 \AA) \\
\text { and MR zonal wind }\end{array}$ & 0.277 & $6.1 \cdot 10^{-14}$ & 0.289 & $4.6 \cdot 10^{-15}$ & 0.086 & 1.887 \\
\hline $\begin{array}{l}2018 \text { FPI ( } 6300 \AA) \\
\text { and MR meridional wind }\end{array}$ & 0.155 & $1.3 \cdot 10^{-5}$ & 0.171 & $1.7 \cdot 10^{-6}$ & 0.062 & 0.135 \\
\hline $\begin{array}{l}2018 \text { FPI ( } 8430 \AA) \\
\text { and MR zonal wind }\end{array}$ & 0.657 & $5.3 \cdot 10^{-88}$ & 0.666 & $2.3 \cdot 10^{-91}$ & 0.589 & -2.065 \\
\hline $\begin{array}{l}2018 \text { FPI }(8430 \AA) \\
\text { and MR meridional wind }\end{array}$ & 0.464 & $4.8 \cdot 10^{-42}$ & 0.547 & $8.7 \cdot 10^{-61}$ & 0.357 & -2.071 \\
\hline
\end{tabular}

$P$ is the Pearson correlation coefficient; $S$ is the Spearman correlation coefficient; p-val $(P, S)$ is the acquisition probability of random correlation with a given value for both the coefficients; linear regression coefficients $A, B$ are slope and shift respectively. 
where $U, V$ are the horizontal wind components; $A$ is the wind velocity modulus; $\theta$ is the wind direction; the subscripts $\mathrm{A}$ and $\mathrm{T}$ indicate locations of the instruments (Angarsk and Tory). The wind velocity at one observation point can be expressed through the wind velocity at another observation point as follows:

$$
A_{\mathrm{T}}=\alpha A_{\mathrm{A}} e^{i \theta_{\mathrm{A}}+i \delta}
$$

where $\alpha$ is the scale factor of variation in the wind velocity modulus, $\delta$ is the additive variation in the wind direction. In other words, the wind at the point $\mathrm{T}$ is $\alpha$ times stronger than that at the point $\mathrm{A}$, and its direction differs by $\delta$ radians from that at the point $\mathrm{A}$. Then, to determine differences between wind velocity moduli and direction, we can simply calculate the ratio of complex representations of the horizontal wind at different observation points:

$$
\frac{A_{\mathrm{T}}}{A_{\mathrm{A}}}=\frac{\alpha A_{\mathrm{A}} e^{i \theta} A^{+i \delta}}{A_{\mathrm{A}} e^{i \theta} A}=\alpha e^{i \delta} .
$$

The modulus of the obtained complex value characterizes the ratio of total wind velocity moduli, and the argument characterizes the difference in wind direction for different observation points. The resulting complex values of variations for each individual observation can be statistically analyzed. Histograms of variations in the total wind velocity and its direction for all available datasets are shown in Figures 4, 5 (for 2017 and 2018 respectively). These distributions (Figures 4,5 ) confirm the above conclusions about greater similarity in the behavior of the wind measured with FPI in the $843 \mathrm{~nm}$ line and MR, because the ratio of total wind velocity moduli for these datasets has a maximum of about unity, and the difference between wind directions has a maximum near zero. The wind variation for the data from FPI data in the $557.7 \mathrm{~nm}$ line and MR has a total wind velocity ratio close to unity, but the wind direction in these datasets differs by $30-40^{\circ}$ for both 2017 and 2018 . The wind variation for the data from FPI in the 557.7 $\mathrm{nm}$ line and from MR suggests that the wind velocity at $\sim 250 \mathrm{~km}$ is $2-3$ times faster and the wind direction also differs by $\sim 40^{\circ}$ for 2017 and 2018.
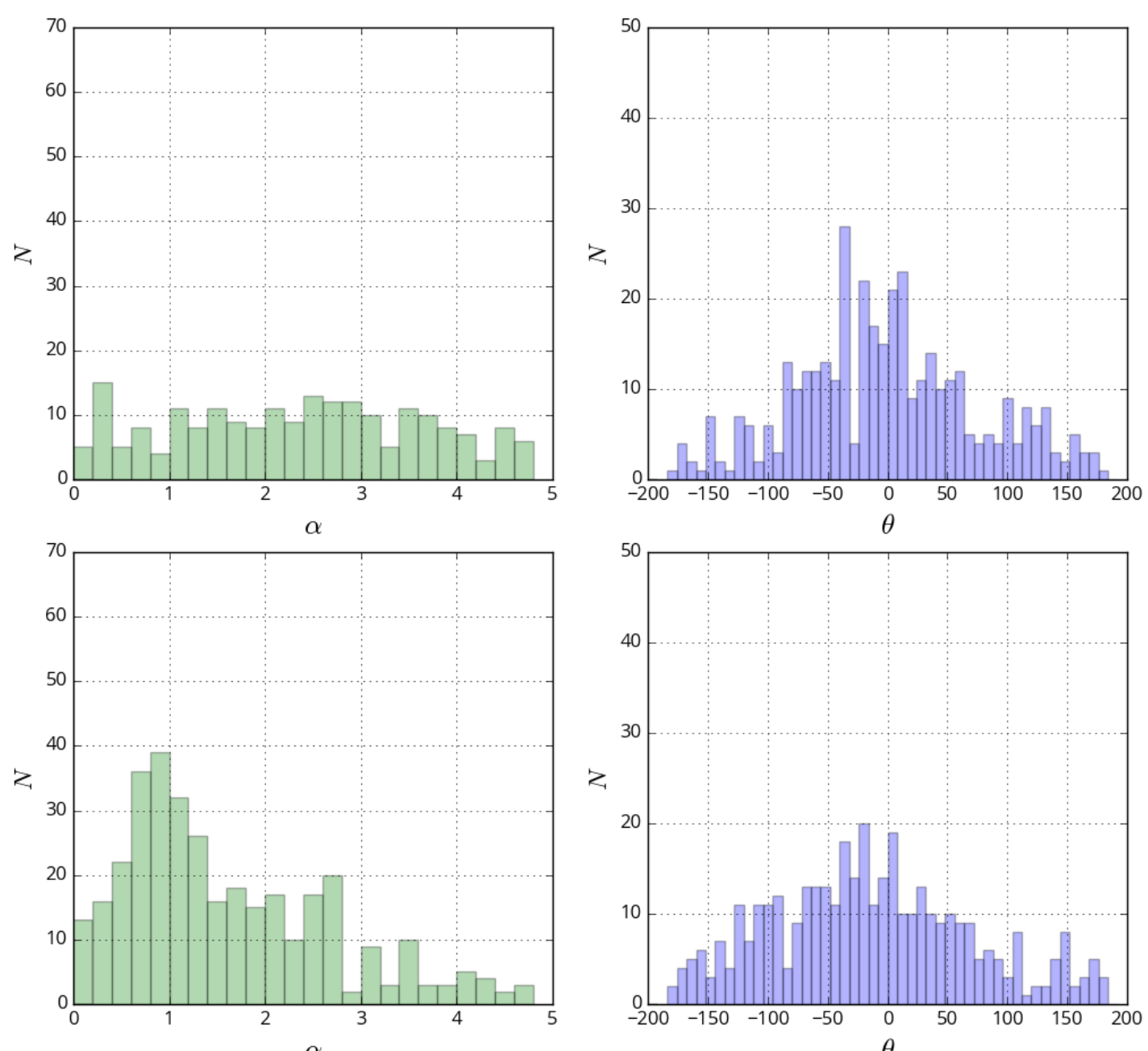

Figure 4. Histograms of variations in the total wind velocity and its direction over the period from January to June 2017 obtained with FPI in the $630 \mathrm{~nm}$ line at $\sim 250 \mathrm{~km}$ and MR (top); with FPI in the $557.7 \mathrm{~nm}$ line at $\sim 100 \mathrm{~km}$ and with MR (bottom). Wind velocity moduli ratio (left); difference in wind direction in degrees (right) 

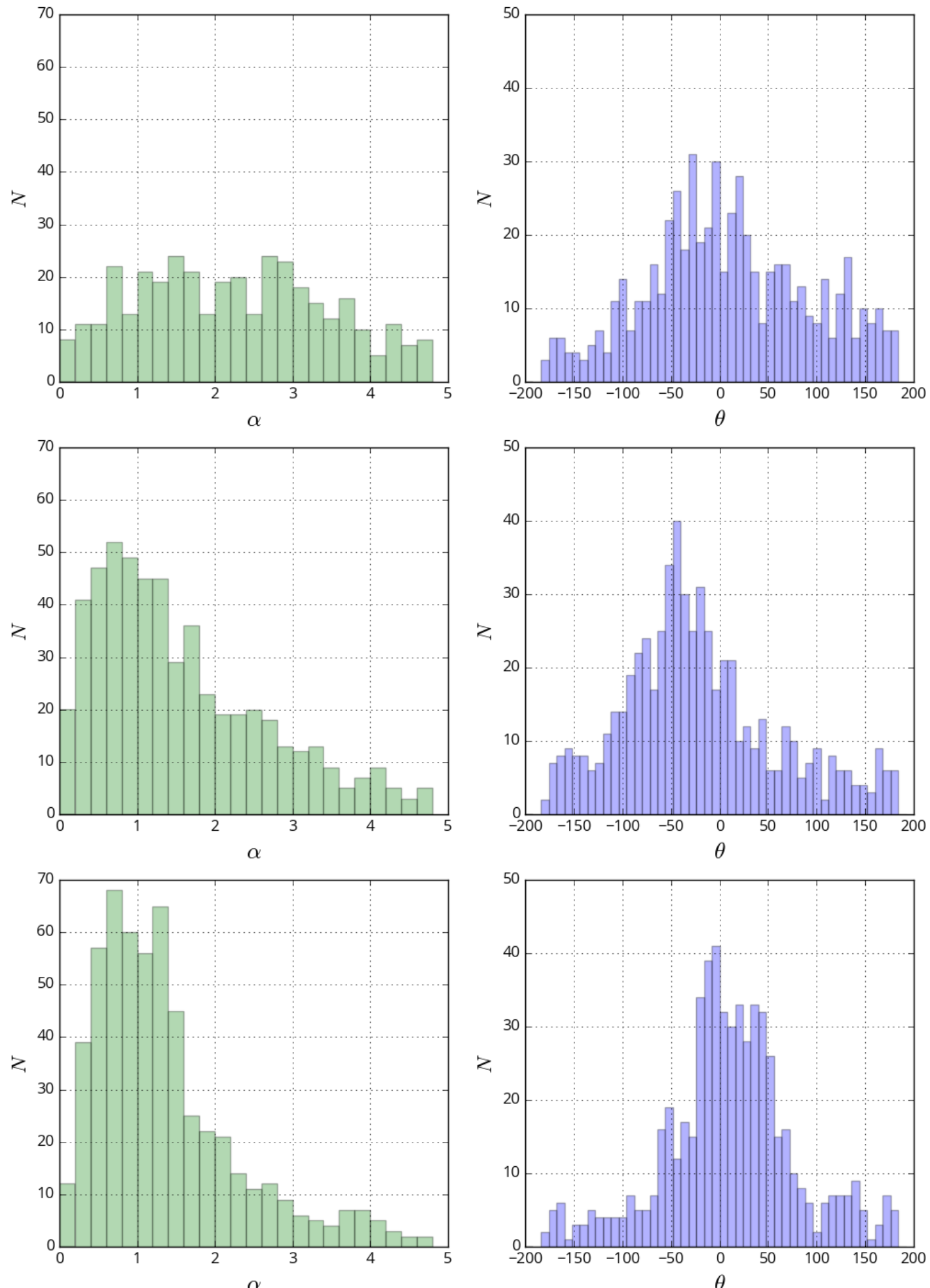

Figure 5. Histogram of variations in the total wind velocity and direction over the period from January to March 2018 obtained with: FPI in the $630 \mathrm{~nm}$ line at $\sim 250 \mathrm{~km}$ and MR (top); FPI in the $557.7 \mathrm{~nm}$ line at $\sim 100 \mathrm{~km}$ and MR (middle). Wind velocity moduli ratio (left); difference in wind direction in degrees (right)

For the wind variations the statistical similarity in the information obtained with FPI in the 630 and 557.7 $\mathrm{nm}$ lines and with MR for different years of observations is obvious. Some differences can be attributed to different intervals of observations (January-February 2018 and February-May 2017) and to irregularity of data (gaps in Figures 2,3). Nevertheless, the proposed method of comparing the wind velocities at different observation points can be also adopted to analyze seasonal and diurnal or height wind dynamics, if datasets provide the statistical integrity of information. 

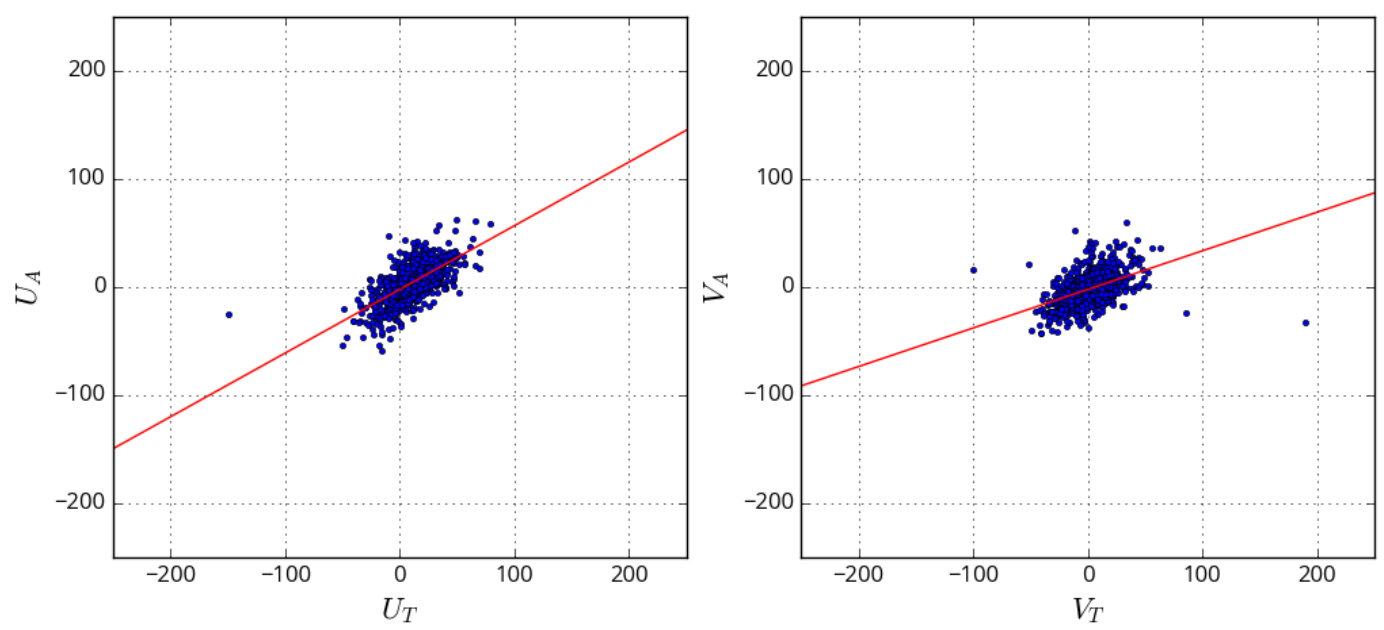

Figure 6. Original data and linear regression of the zonal (left) and meridional (right) wind recorded with different instruments at one height. Noteworthy is the distortion of the linear regression for the meridional wind caused by erroneous random large-amplitude fluctuations

\section{CONCLUSION}

The analysis has shown that the methods of horizontal wind observations are valid because the obtained data are similar for roughly the same observing conditions. Peculiarities of wind behavior during the SSW event in 2017, which were found at a height of $100 \mathrm{~km}$ and were not observed at 90 and $250 \mathrm{~km}$, are a quite interesting local feature of this event, which requires further investigation. Variations in the moment of the diurnal zonal wind inversion at 250 $\mathrm{km}$ during geomagnetic disturbances are also an interesting feature, which can be used to quantify effects of geomagnetic disturbances on the neutral atmosphere circulation. The described method of comparing winds at two points is likely to be more suitable for automated data analysis than traditional correlation characteristic-comparing methods. Quantitative assessments of the comparison, derived from distributions, will be less sensitive to the fluctuations that can greatly distort linear regression coefficients during automated data processing (see, e.g., Figure 6).

As shown in the histograms, the ratio of the horizontal neutral wind velocity measured with FPI in the 843 $\mathrm{nm}$ line to that measured with MR is close to unity, and the angle between wind directions is close to zero. This indicates the identity of the wind observed with the two instruments. The ratio of the wind velocity measured with FPI in the $557.7 \mathrm{~nm}$ line to that measured with MR is also close to unity, but the angle between wind directions is about $50^{\circ}$. This suggests that there is a wind shift caused by a change of wind direction with height. The fact that the absolute wind velocity measured with FPI is 2.5 times higher than that measured with MR and the wind direction measured with FPI in the $630 \mathrm{~nm}$ line differs by $30-40^{\circ}$ from that obtained with MR indicates that the instruments observed completely different regions of the atmosphere.

The results were obtained using the equipment of Center for Common Use «Angara» [http://ckp-rf.ru/ckp/
3056]. The processing and statistical analysis of observations were funded by RFBR grant No. 18-05-00594 A. The study of the influence of stratospheric warming events and geomagnetic storms was carried out with budgetary funding of Basic Research Program II.12.

\section{REFERENCES}

D’yachenko V.A., Lysenko I.A., Portnyagin Yu.I. Klimaticheskii rezhim vetra nizhnei termosfery [Climatic regime of the lower thermosphere wind]. Obninsk, VNIIGMI-MCD Publ., 1986. 114 p. (In Russian).

East S.A., Meredith N.P., Harris M.J., Rees D., Wickwar V.B., Monson I.K., Muller H.G. First summer results on winds in the upper mesosphere derived from the $843 \mathrm{~nm}$ hydroxyl emissions measured from the Bear Lake Observatory, Utah. J. Atmos. Terr. Phys. 1995, vol. 57, no. 9, pp. 995-1008. DOI: 10.1016/0021-9169(94)00086-4.

Fujii J., Nakamura T., Tsuda T., Shiokawa K. Comparison of winds measured by MU radar and Fabry-Perot interferometer and effect of OI5577 airglow height variations. $J$. Atmos. Solar-Terr. Phys. 2004, vol. 66 no. 6-9, pp. 573-583. DOI: 10.1016/j.jastp.2004.01.010.

Hines C.O., Adams G.W., Brosnahan J.W., Djuth F.T., Sulzer M.P., Tepley C.A., van Baelen J.S. Multi-instrument observations of mesospheric motions over Arecibo: comparisons and interpretations. J. Atmos. Terr. Phys. 1993, vol. 55, no. 3, pp. 241-287. DOI: 10.1016/0021-9169(93)90069-B.

Hu G.-Y., Ai Y., Zhang Y.-G., Shan X., Gu J. Thermospheric wind observation by a scanning Fabry-Perot interferometer during MERINO campaign. Acta Geophysica Sinica. 2014, vol. 57, no. 11, pp. 3688-3694. DOI: $10.6038 /$ cjg20141123.

Jacobi Ch. Meteor heights during the recent solar minimum. Adv. Radio Sci. 2014, vol. 12, pp. 161-165. DOI: $10.5194 /$ ars-12161-2014.

Jee G., Kim J.-H., Lee C., Kim Y.H. Ground-based observations for the upper atmosphere at King Sejong Station, Antarctica. J. Astron. Space Sci. 2014, vol. 31, no. 2, pp. 169-176. DOI: 10.5140/JASS.2014.31.2.169.

Jiang G.Y., Xu J.Y., Yuan W., Ning B.Q., Wan W.X., $\mathrm{Hu}$ L.H. A comparison of mesospheric winds measured by FPI and meteor radar located at 40 N. Science China Tech- 
nological Sciences. 2012, vol. 55, no. 5, pp. 1245-1250. DOI: 10.1007/s11431-012-4773-1.

Plagmann M., Marsh S.H., Baggaley W.J., Bennett R.G.T., Deutsch K.A., Fraser G.J., Hernandez G., Lawrence B.N., Plank G.E., Smith R.W. Annual variation of airglow heights derived from wind measurements. Geophys. Res. Lett. 1998, vol. 25 , no. 24, pp. 4457-4460. DOI: 10.1029/1998GL900212.

Salah J.E., Goncharenko L.P., Sipler D.P., Clark R.R., Tate R.J. Common-volume measurements of mesospheric winds using radar and optical instruments: 1 . Comparison of observations. J. Atmos. Solar-Terr. Phys. 1999, vol. 61, no. 17, pp. 1259-1271. DOI: 10.1016/S1364-6826(99)00085-1.

Shiokawa K., Otsuka Y., Ogawa T., Kawamura S., Yamamoto M., Fukao S., Nakamura T., Tsuda T., Balan N., Igarashi K., Lu G., Saito A., Yumoto K. Thermospheric wind during a storm-time large-scale traveling ionospheric disturbance. J. Geophys. Res.: Space Phys. 2003, vol. 108, no. A12, no. 1423. DOI: $10.1029 / 2003 J A 010001$.

Vasilyev R.V., Artamonov M.F., Beletsky A.B., Zherebtsov G.A., Medvedeva I.V., Mikhalev A.V., Syrenova T.E. Registering upper atmosphere parameters in East Siberia with Fabry-Perot interferometer KEO Scientific "Arinae". SolarTerrestrial Physics. 2017, vol. 3, no. 3, pp. 61-75. DOI 10.12737/stp-33201707.

Vasilyev R.V., Klimenko M.V., Klimenko V.V. Some features of the behavior of horizontal wind velocity in winter at heights of the upper atmosphere in Eastern Siberia. XXII Mezhdunarodnyi simpozium "Optika atmosfery i okeana. Fizika atmosfery”. Materialy. [Proc. XXIII International Symposium "Atmospheric and Oceanic Optics. Atmospheric Physics"] Conf. D. Irkutsk, 2017, pp. D252-D255. (In Russian).
Vergasova G.V., Kazimirovsky E.S. External impact on wind in the mesosphere/lower thermosphere region. Geomagnetism and Aeronomy. 2010, vol. 50, no. 7, pp. 914-919. DOI: $10.1134 / \mathrm{S} 0016793210070145$.

Wu Q., Maute A., Yudin V., Goncharenko L., Noto J., Kerr R., Jacobi C. Observations and simulations of midlatitude ionospheric and thermospheric response to the January 2013 stratospheric sudden warming event. J. Geophys. Res.: Space Phys. 2016, vol. 121, no. 9, pp. 8995-9011. DOI: 10.1002/2016JA023043.

Yu T., Zuo X., Xia C., Li M., Huang C., Mao T., Zhang X., Zhao B., Liu L. Peak height of OH airglow derived from simultaneous observations a Fabry-Perot interferometer and a meteor radar. J. Geophys. Res.: Space Phys. 2017, vol. 122, no. 4, pp. 4628-4637. DOI: 10.1002/2016JA023743.

URL: http://ckp-rf.ru/ckp/3056 (accessed March 15, 2018).

URL: https://acd-ext.gsfc.nasa.gov/Data_services/met/ann data.html (accessed March 15, 2018).

How to cite this article

Vasilev R.V., Artamonov M.F., Merzlyakov E.G. Comparative statistical analysis of neutral wind in mid-latitude mesosphere / lower thermosphere based on meteor radar and Fabry-Perot interferometer data Solar-Terrestrial Physics. 2018. vol. 4, iss. 2. pp. 49-57. DOI: $10.12737 /$ stp-42201808. 